\title{
Study on the Clinical Safe and Effective Methods of Arsenic-Containing Compound-Qinghuang Powder in the Treatment of Myelodysplastic Syndrome
}

\author{
Qianzhe Zhu, Zhongyang Deng, Shirong Zhu, Pan Zhao, Mingjing Wang, and Xiaomei Hu \\ Department of Hematology, Xiyuan Hospital, China Academy of Chinese Medical Sciences, Beijing 100091, China \\ Correspondence should be addressed to Xiaomei Hu; huxiaomei_2@163.com
}

Received 3 May 2017; Revised 21 August 2017; Accepted 10 September 2017; Published 16 November 2017

Academic Editor: I-Min Liu

Copyright (C) 2017 Qianzhe Zhu et al. This is an open access article distributed under the Creative Commons Attribution License, which permits unrestricted use, distribution, and reproduction in any medium, provided the original work is properly cited.

Objective. To establish the clinical safe and effective methods of arsenic-containing compound-Qinghuang Powder (compoundQHP) in the treatment of myelodysplastic syndrome (MDS). Methods. 200 patients with MDS were treated with compound-QHP (daily dose of $0.1 \mathrm{~g}$ realgar). The blood arsenic concentrations (BACs) were detected by atomic fluorescence spectrophotometry (HF-AFS). After treatment for 1 month, the patients were randomly divided into group A and group B when the BACs were less than $20 \mu \mathrm{g} / \mathrm{L}$. Daily dose of realgar was maintained in group A and it was increased to that when the BACs were more than $20 \mu \mathrm{g} / \mathrm{L}$ in group B. The BAC and clinical efficacy and safety in two groups were compared at the end of the treatment with compound-QHP. Results. The average BAC of group B was significantly higher than that of group $\mathrm{A}(P<0.01)$. The rates of hematology improvement and reduced transfusion were significantly higher in group B than in group A $(P<0.05)$. The HGB, ANC, and PLT significantly increased in group $\mathrm{B}$ after treatment $(P>0.05)$. Conclusions. Monitoring the $\mathrm{BAC}$ and adjusting the daily dose of realgar to increase the effective BAC and then improving efficacy without increasing the clinical toxicity are the clinical safe and effective methods in the treatment of MDS.

\section{Introduction}

Myelodysplastic syndrome (MDS) is a clonal disorder of hematopoietic stem or progenitor cell which is characterized by ineffective hematopoiesis of the bone marrow, long-term progressively refractory anemia, and frequent development of leukemia [1].

Qinghuang Powder (QHP) is made of indigo naturalis and realgar and realgar is an arsenic-containing mineral with toxicity. Our previous study had reported that QHP was effective in treating MDS [2,3], and the clinical efficacy was related to the blood arsenic concentrations when they are higher than $20 \mu \mathrm{g} / \mathrm{L}$ [4]. Low arsenic concentration of blood of patients with QHP has poor treatment effect. Compound-Qinghuang Powder (compound-QHP) was a modified prescription based on the traditional QHP that could better ensure the blood arsenic concentrations by decreasing the side digestive effect $[5,6]$. Our study tested the blood arsenic concentrations of patients with MDS and increased the dosage of realgar for patients whose blood arsenic concentrations were less than $20 \mu \mathrm{g} / \mathrm{L}$. The aim of the present study was to achieve a proper clinical application of compound-QHP that could improve the efficacy and decreased the adverse events by modifying the dosage of realgar and improving the blood arsenic concentrations.

\section{Materials and Method}

2.1. Patients. Inclusion criteria were as follows: (1) patients met the diagnosis and classification of MDS according to the diagnosis of MDS and the WHO MDS criteria in 2007 $[7,8]$, and the prognosis standard of MDS adopted the revised international prognosis scoring system (IPSS-R) [9]. (2) Patients did not use arsenic-containing drugs for the past 2 months before the enrollment. (3) The age of patients is between 18 and 75 years. (4) Patients must have signed an informed consent form. 
Exclusion criteria were as follows: (1) patients with severe diseases in heart, liver, kidney, and peripheral nerves; (2) woman with pregnancy or lactation; (3) patients with severe mental illness; (4) patients in other trials.

A final number of 200 patients who met the diagnosis and classification of MDS were collected; all of them were admitted to the Department of Hematology in Xiyuan Hospital, China Academy of Chinese Medical Sciences, ranging from March 2015 to November 2016. The age of them was between 18 and 72 years and the average age was $56.5 \pm 15.5$ years. Patients were orally administered with compound-QHP, prepared by Preparation Laboratory of Xiyuan Hospital, at a daily dose of $2.7 \mathrm{~g}$ including realgar $0.1 \mathrm{~g}$, indigo naturalis $0.2 \mathrm{~g}$, white peony root $0.96 \mathrm{~g}$, Atractylodis macrocephala Koidz 0.48 g, Radix Ledebouriellae 0.48 g, and Pericarpium Citri Reticulatae $0.48 \mathrm{~g}$.

2.2. Experimental Design. The blood arsenic concentration of 200 patients was detected by atomic fluorescence spectrophotometry (HF-AFS) after one month's treatment with compound-QHP. We adopted randomized, single blind, and case control methods to divide them into group A and group $\mathrm{B}$ for patients whose arsenic concentrations were less than $20 \mu \mathrm{g} / \mathrm{L}$ after the first month of treatment. Daily dose of $0.1 \mathrm{~g}$ realgar was maintained during the course of treatment in group $\mathrm{A}$, while it was increased by $0.1 \mathrm{~g}$ each time until the blood arsenic concentrations were more than $20 \mu \mathrm{g} / \mathrm{L}$ in group B. A period of three months was considered as a course of treatment and the patients received 2 courses of treatments. The blood arsenic concentrations were tested during the course of treatment at 1,3, and 6 months as three time points. The dose of realgar would be reduced by half when the blood arsenic concentrations were more than $140 \mu \mathrm{g} / \mathrm{L}$, and treatment would be discontinued when the blood arsenic concentrations were more than $940 \mu \mathrm{g} / \mathrm{L}$, which were determined with reference to the reported peak safe concentrations of patients receiving intravenous injection of arsenous acid. All patients continued to receive the compound-QHP after the end of clinical trials.

Among 200 patients, 148 cases were only treated with compound-QHP; 26 of them had previously been accepted Stanozolol and had stopped at least one month before the treatment with compound-QHP. Another 52 cases were treated with combination of compound-QHP and Stanozolol (2 4 mg/d). Transfusion of blood components was used as the supportive therapy if necessary.

2.3. Assessment of Response and Safety Analysis. All patients received assessment of response after the treatment according to IWG 2006 criteria of MDS [10].

The safety assessment of treatment with compound-QHP included two aspects, which were symptoms and organic functions of adverse reactions. Side effect symptoms included nausea, anorexia, abdominal pain, diarrhea, limb numbness, skin keratinization, and swelling.

Adverse reaction grading standards were in accordance with the 2002 Clinical Guideline of New Drugs for Traditional Chinese Medicine: (1) light grade: the patients could tolerate the side effect of treatment and continue the study without other disposition. And it had no significant damage of health. (2) Moderate grade: the patients' health was damaged and they could not tolerate the side effect. (3) Severe grade: the side effect symptom jeopardized the life of the subjects who were disabled or died. They need to stop the treatment and dispose immediately. The organic functions were analyzed by myocardial enzymes, liver functions, and renal functions.

2.4. Statistical Analysis. All blood arsenic concentrations were detected in triplicate. Statistical analysis was performed by using GraphPad Prism software version 6.0. Measurement data was compared with test and expressed as mean \pm standard deviation. Counting data was compared with chisquare test and expressed as a percentage. $P<0.05$ was considered to indicate a statistical difference.

\section{Result}

3.1. General Characteristics of Patient Population. 60 of 200 patients whose blood arsenic was less than $20 \mu \mathrm{g} / \mathrm{L}$ after the first month of treatment were randomly divided into group A (Control group) and group B (Experimental group). Daily dose of realgar was maintained in group $\mathrm{A}$, while that was increased until the blood arsenic concentrations were more than $20 \mu \mathrm{g} / \mathrm{L}$ in group B. Nine patients dropped out by reason of referral (Control group: $N=4$; Experimental group: $N=$ 5 ), and 3 patients dropped out by reason of poor compliance (Control group: $N=2$; Experimental group: $N=1$ ). Finally, 48 cases were collected in this study (Control group: $N=$ 24; Experimental group: $N=24$ ). Table 1 summarized the general characteristics of 48 patients. There were no statistical difference between group $\mathrm{A}$ and group $\mathrm{B}$ in gender $(P>0.05)$, age $(P>0.05)$, karyotype $(P>0.05)$, classification of $\mathrm{WHO}$ $(P>0.05)$, IPSS-R Scores $(P>0.05)$, and the blood arsenic concentrations $(P>0.05)$, respectively.

3.2. The Blood Arsenic Concentrations and the Treatment Efficacy. The average blood arsenic concentrations of group A after two courses of the treatment were $21.39 \pm 3.49 \mu \mathrm{g} / \mathrm{L}$, while that in group B increased to $44.43 \pm 10.54 \mu \mathrm{g} / \mathrm{L}$. There was a significant difference between two groups $(P<0.01)$ (Figure 1)

After the treatment, 7 out of 24 patients in group A achieved the hematological improvement; 14 patients were in stable condition while another 3 patients had no response to treatment. Five patients depended on transfusion of red blood cells before the treatment; 1 out of them was in no need for transfusion after the treatment. The rate of hematological improvement was $29.2 \%$. In group B, 13 patients achieved the hematological improvement and 8 patients were in stable condition while another 3 patients had no response to treatment. Seven patients depended on transfusion of red blood cells before the treatment, 5 out of them were independent of transfusion and in 1 patient the interval of transfusion was extended after the treatment. The reduced transfusion rate after the treatment in group B $(71.43 \%)$ was significantly higher than that in group A $(20 \%)(P<0.05)$. The rate of hematological improvement in group B was $54.2 \%$, which was 
TABLE 1: General characteristics of 48 patients treated with compound-QHP.

\begin{tabular}{lcc}
\hline Group & $\begin{array}{c}\text { Group A } \\
N=24\end{array}$ & $\begin{array}{c}\text { Group B } \\
N=24\end{array}$ \\
\hline $\begin{array}{l}\text { Gender [N/(\%)] } \\
\quad \text { Male }\end{array}$ & $7(29.2)$ & $10(41.7)$ \\
$\quad$ Female & $17(70.8)$ & $14(58.3)$ \\
\hline Average age (years) & $51.9 \pm 16.7$ & $52.4 \pm 14.5$ \\
\hline Karyotype risks & $12(50)$ & $10(41.67)$ \\
$\quad$ Very good/good & $7(29.17)$ & $8(33.33)$ \\
$\quad$ Intermediate & $5(20.84)$ & $6(25.0)$ \\
$\quad$ Poor/very poor & & \\
\hline Diagnosis according to WHO & & \\
[N/(\%)] & $20(83.3)$ & $19(79.2)$ \\
$\quad$ RA/RCMD/RARS & $3(12.5)$ & $3(12.5)$ \\
RAEB1 & $1(4.2)$ & $2(8.4)$ \\
$\quad$ RAEB2 & & \\
\hline IPSS-R score [N/(\%)] & $5(23.8)$ & $6(25.0)$ \\
$\quad$ Very low/low & $17(70.8)$ & $16(66.7)$ \\
Intermediate & $2(8.3)$ & $2(8.3)$ \\
high/very high & $15.63 \pm 3.83$ & $16.31 \pm 2.47$ \\
\hline The blood arsenic concentrations & & \\
after one month of treatment $(\mu \mathrm{g} / \mathrm{L})$ & & \\
\hline
\end{tabular}



FIGURE 1: The comparison of blood arsenic concentrations between two groups after the treatment, ${ }^{*} P<0.01$.

significantly higher than that in group A $(29.2 \%)(P<0.05)$ (Figure 2)

The cell counts including hemoglobin (HGB), absolute neutrophil count (ANC), and platelets (PLT) in peripheral blood of group A had no significant difference after the treatment $(P>0.05)$, while those counts in group B had significantly increased. In group B, the HGB increased from



FIgURE 2: The comparison of hematological improvement rate between group A and group B after the treatment, ${ }^{*} P<0.05$.

$75.59 \pm 24.94 \mathrm{~g} / \mathrm{L}$ to $86.12 \pm 26.35 \mathrm{~g} / \mathrm{L}(P<0.05)$. The ANC increased from $1.02 \pm 0.37 \times 10^{9} / \mathrm{L}$ to $1.28 \pm 0.60 \times 10^{9} / \mathrm{L}$ $(P<0.05)$, and the PLT increased from $50.11 \pm 33.55 \times 10^{9} / \mathrm{L}$ to $61.89 \pm 36.93 \times 10^{9} / \mathrm{L}(P<0.01)$ (Table 2).

\subsection{Side Effect}

Clinical Adverse Symptoms. Two patients who received the treatment in group A had symptoms of diarrhea, and 1 out of 2 patients had a complication of gastric malaise. In group B, 2 patients had symptoms of diarrhea. Overall, the clinical adverse symptoms are light degree, and no patients need to stop the therapy (Table 3).

3.4. Organic Function. During the 6-month treatment period, 3 patients in group A were with liver dysfunction before the treatment ( 2 cases with high level of ALT and 1 case with high level of GGT), while 1 of 3 patients recovered and 2 of 3 patients alleviated after the treatment. In group B, 6 patients were with liver dysfunction (6 cases with high level of ALT) before the treatment, while 2 of 6 patients recovered and 4 of 6 patients alleviated after the treatment. Before treatment, five patients were with increased cardiac enzyme in group A (2 cases with high level of $\mathrm{LDH}, 4$ cases with high level of $\mathrm{HBDH}$ ) and 1 of 5 patients recovered and 4 of 5 patients alleviated after the treatment. Four patients were with increased cardiac enzyme in group B (4 cases with high level of LDH, 4 cases with high level of $\mathrm{HBDH}$ ), and 1 of 4 patients recovered and 3 of 4 patients alleviated after the treatment. No patients were with renal dysfunction before the treatment. There were no new cases with abnormal liver functions, cardiac enzymes, and renal functions (Table 4).

\section{Discussion}

There has been a long history of treatment with traditional Chinese arsenic-containing medicine [11], which mainly consists of arsenic trioxide $\left(\mathrm{As}_{2} \mathrm{O}_{3}\right)$ and realgar $\left(\mathrm{As}_{2} \mathrm{~S}_{2}\right)$. Traditional Chinese arsenic-containing medicine in treating $\mathrm{MDS}$ 
TABLE 2: The comparison of the cell counts in peripheral blood between two groups after the treatment.

\begin{tabular}{lcccc}
\hline Group & Time & $\begin{array}{c}\text { ANC }<1.5 \\
\left(\times 10^{9} / \mathrm{L}\right)\end{array}$ & $\begin{array}{c}\text { HGB }<120 \\
(\mathrm{~g} / \mathrm{L})\end{array}$ & $\begin{array}{c}\text { PLT }<125 \\
\left(\times 10^{9} / \mathrm{L}\right)\end{array}$ \\
\hline A & $\begin{array}{c}\text { Before the } \\
\text { treatment } \\
\text { After the treatment } \\
\text { Before the }\end{array}$ & $0.90 \pm 0.41$ & $74.00 \pm 16.16$ & $56.95 \pm 34.96$ \\
B & $1.15 \pm 0.60$ & $78.17 \pm 22.02$ & $57.00 \pm 34.23$ \\
& treatment & $1.02 \pm 0.37$ & $75.59 \pm 24.94$ & $50.11 \pm 33.55$ \\
& After the treatment & $1.28 \pm 0.60^{*}$ & $86.12 \pm 26.35^{*}$ & $61.89 \pm 36.93^{*}$ \\
\hline
\end{tabular}

In group B, the levels of HBG, ANC, and PLT after treatment were significantly higher than that before treatment, respectively. ${ }^{*} P<0.05$.

TABLE 3: Clinical adverse symptoms of group A and group B.

\begin{tabular}{lcc}
\hline Symptoms & \multicolumn{2}{c}{ Number of patients (\%) } \\
& Group A & Group B \\
\hline Gastric malaise & $1(4.17)$ & 0 \\
Anorexia and nausea & 0 & 0 \\
Diarrhea & $2(8.33)$ & $2(8.33)$ \\
Numbness of limbs & 0 & 0 \\
Skin keratosis & 0 & 0 \\
Edema & 0 & 0 \\
\hline
\end{tabular}

has been a popular area of research recently [2,3], which is characterized by its better curative efficacy, agreeable price, and less side effect that could be tolerated by patients. Data from the research suggested that the oral dose of realgar $\left(\mathrm{As}_{2} \mathrm{~S}_{2} / \mathrm{As}_{4} \mathrm{~S}_{4}\right)$ was usually more than $0.9 \mathrm{~g} / \mathrm{d}$ in the treatment of hematological malignancy, while the dose was normally used as $3 \mathrm{~g} / \mathrm{d}$ with the blood arsenic concentrations ranging from 20 to $110 \mu \mathrm{g} / \mathrm{L}$. The mainly adverse reactions of those doses were side digestive effects. The blood arsenic concentration could reach $900 \mu \mathrm{g} / \mathrm{L}$ with the intravenous drip of the $\mathrm{As}_{2} \mathrm{O}_{3}$ at $10 \mathrm{mg}$ per day, while no patients appeared to have severe side effect [12].

QHP, which consisted of natural indigo and realgar, was the effective drug in treating hematological diseases developed by hematology department of Xiyuan Hospital after a long period of clinical practice $[2-6,11]$. The properties of realgar were described as warmth, acridity, and toxicity in traditional Chinese medicine. The dose of realgar has been changed several times in Chinese Pharmacopoeia: oral dose of realgar ranged from 0.3 to $1.0 \mathrm{~g}$ per day according to version in 1977 , from 0.15 to $0.3 \mathrm{~g}$ per day according to version in 1990 , and from 0.05 to $0.1 \mathrm{~g}$ per day according to version in 1995-2015 [13].

Previous studies have suggested that QHP in treating patients with MDS have a great efficacy except some patients with no response [2]. The side effect increased and particularly the digestive reaction of realgar increased randomly for better efficacy. Further study has suggested that the efficacy on patients with QHP was related to the blood arsenic concentrations [4] and enough blood arsenic concentrations were the key to obtain the curative effect in treating MDS. Diarrhea could reduce the absorption of QHP in digestive tract and decrease the efficacy on account of insufficient blood arsenic concentrations.

Compound-QHP have optimized the component of QHP, and white peony root, Atractylodis macrocephala Koidz, Radix Ledebouriellae, and Pericarpium Citri Reticulatae were added in the new prescription in addition to indigo naturalis and realgar to prevent the gastrointestinal adverse reaction. Our previous research suggested that compound-QHP in treating patients with MDS decreased adverse digestive reactions and increased efficacy compared to those who received QHP. The previous in vitro study suggested the active ingredients of realgar $\left(\mathrm{As}_{2} \mathrm{~S}_{2}\right)$ as the monarch drug in compound-QHP that could induce the apoptosis and promote the differentiation in a dose-dependent manner for MDS/AML [14-17].

Our previous studies have showed that the lowest blood arsenic concentration of efficacy is $20 \mu \mathrm{g} / \mathrm{L}$ [4]. In this study, the patients who received compound-QHP with insufficient blood arsenic concentrations $(<20 \mu \mathrm{g} / \mathrm{L})$ were randomly assigned to group A and group B. Daily dose of realgar was maintained in group $\mathrm{A}$, while that was increased until the blood arsenic concentrations were more than $20 \mu \mathrm{g} / \mathrm{L}$ in group $\mathrm{B}$. The concentrations after the treatment in group $\mathrm{B}$ were significantly higher than those in group A $(44.43 \pm 10.54$ versus $21.39 \pm 3.49 \mu \mathrm{g} / \mathrm{L}, P<0.05)$. The rate of hematology improvement was significantly higher in group $B$ than that in group A ( $54.2 \%$ versus $29.2 \%, P<0.05)$. The study suggested that increasing the blood arsenic concentrations is important to develop the efficacy with compound-QHP. The greater dose $(0.2 \mathrm{~g} / \mathrm{d})$ of realgar could increase the concentrations in treating MDS without more side effects. The increased concentration is significantly lower than that in other methods of usage with arsenical in literature [12]. The patients of the two groups were both followed for 3 months after the six-month treatment.

There were few adverse digestive reactions with light grade in patients with compound-QHP, and those were gradually decreased with the treatment in some patients. The result suggested that patients with the treatment of compound-QHP could tolerate the side effect and there is no need to stop the therapy. Some patients with liver dysfunction and abnormal cardiac enzyme are related to testosterone and long-term of anemia, respectively, and some of them could recover after the treatment. There is no patient with renal dysfunction before the treatment, and there are no new cases with abnormal liver function, cardiac enzyme, and renal 
TABLE 4: Abnormal organic function between group A and group B (number of patients).

\begin{tabular}{lccccc}
\hline \multirow{2}{*}{ Organic function } & Indicator & Group A & & Group B \\
& & BTT & ATT & 2 & BTT \\
\hline \multirow{3}{*}{ Liver functions } & ALT & 2 & 0 & 0 & 0 \\
& AST & 0 & 0 & 0 & 0 \\
\hline \multirow{3}{*}{ Cardiac enzymes } & GGT & 1 & 2 & 4 & 3 \\
& LDH & 2 & 0 & 0 & 3 \\
\hline \multirow{2}{*}{ Renal functions } & HBDH & 4 & 0 & 0 & 0 \\
& CK-MB & 0 & 0 & 0 \\
\hline
\end{tabular}

function during the treatment. Overall, compound-QHP is safe for organic function, which is consistent with previous study.

\section{Conclusions}

Monitoring the blood arsenic concentration and adjusting the daily dose of realgar in order to increase the effective blood arsenic concentration and improving efficacy without increasing the clinical toxicity are the safe and effective clinical methods in the treatment of MDS.

\section{Ethical Approval}

This study was approved by the Clinical Research Ethics Committee of Xiyuan Hospital, Academy of Chinese Medical Sciences, China (Ethics approval number: 2014XL-070-2).

\section{Conflicts of Interest}

The authors declare no conflicts of interest with regard to the publication of this article.

\section{Authors' Contributions}

Xiaomei Hu contributed to the study design; Qianzhe Zhu, Zhongyang Deng, Shirong Zhu, and Xiaomei $\mathrm{Hu}$ wrote the manuscript; Qianzhe Zhu, Zhongyang Deng, Pan Zhao, Mingjing Wang, and Xiaomei Hu performed the research; Qianzhe Zhu, Zhongyang Deng, and Shirong Zhu performed the data processing and statistical analysis. All authors read and agreed on the final version of the manuscript.

\section{Acknowledgments}

This study was supported by a grant from the Beijing Municipal Science \& Technology Commission (no. Z141100006014003) to Xiaomei Hu, a grant from the National Natural Science Foundation of China (no. 81673821) to Xiaomei $\mathrm{Hu}$, and a grant from the Special Research Foundation of Central Level Public Scientific Research Institutes (ZZ10-016) to Xiaomei Hu. The authors thank Professor Wu Xiaosheng, Department of Biochemistry \& Molecular Biology, Mayo Clinic, College Medicine, Rochester, Minnesota, USA, for English checking.

\section{References}

[1] A. Tefferi and J. W. Vardiman, "Myelodysplastic syndromes," The New England Journal of Medicine, vol. 361, no. 19, pp. 1826$1885,2009$.

[2] S. Xu, R. Ma, X.-M. Hu et al., "Clinical observation of the treatment of myelodysplastic syndrome mainly with Qinghuang Powder," Chinese Journal of Integrative Medicine, vol. 17, no. 11, pp. 834-839, 2011.

[3] S. Z. Sun, R. Ma, X. M. Hu et al., "Karyotype and DNA-Methylation Responses in Myelodysplastic Syndromes following Treatment with Traditional Chinese Formula Containing Arsenic," Evidence-Based Complementary and Alternative Medicine, vol. 2012, Article ID 969476, 8 pages, 2012.

[4] J. L. Ma, W. W. Qu, and X. M. Hu, "Correlationship of Clonal Selection of Treatmentwith Arsenic-containing Formula Qinghuang Powder in vivo Effects of Arsenic in Patients with Myelodysplastie Syndrome," Chinese Journal of Information on Traditional Chinese Medicine, vol. 20, no. 6, pp. 8-10, 2013 (Dutch).

[5] Y. Wang, S. Fang, M. M. Song et al., "Safety of compound Qinghuang Powder in patients with myelodysplastic syndromes," International Journal of Traditional Chinese Medicine, vol. 36, no. 12, pp. 1074-1077, 2014 (Chinese).

[6] Y. Wang, S. Fang, Z. Y. Deng et al., "Compound Qinghuang Powder in the treatment of patients with myelodysplastic syndromes," International Journal of Traditional Chinese Medicine, vol. 37, no. 12, pp. 1091-1095, 2015 (Chinese).

[7] P. Vanlet, H. P. Horny, J. M. Bennet et al., "Definitions and standards in the diagnosis and treatment of myelodysplatic snydromes: consensus statements and report from a working conference," Leukemia Research, vol. 31, pp. 727-736, 2007.

[8] S. H. Swerdlow, E. Campo, and N. L. Harris, Eds., WHO Classification of Tumours of Haematopoietic and Lymphoid Tissues, IARC, Lyon, France, 2008.

[9] M. T. Voso, S. Fenu, R. Latagliata et al., "Revised International Prognostic Scoring System (IPSS) predicts survival and leukemic evolution of myelodysplastic syndromes significantly better than IPSS and WHO Prognostic Scoring System: validation by the Gruppo Romano Mielodisplasie Italian Regional Database," journal of the American Society of Clinical Oncology, vol. 31, pp. 2671-2677, 2013.

[10] A. Tefferi, G. Barosi, R. A. Mesa et al., "International Working Group (IWG) consensus criteria for treatment response in myelofibrosis with myeloid metaplasia, for the IWG for Myelofibrosis Research and Treatment (IWG-MRT)," Blood, vol. 108, no. 5, pp. 1497-1503, 2006. 
[11] J. Liu, Y. Lu, Q. Wu, R. A. Goyer, and M. P. Waalkes, "Mineral arsenicals in traditional medicines: Orpiment, realgar, and arsenolite," The Journal of Pharmacology and Experimental Therapeutics, vol. 326, no. 2, pp. 363-368, 2008.

[12] J. L. Ma, X. M. Hu et al., "The Research Development of the Pharmacokinetics in Treating Hematological Malignancy with the Chinese Arsenic Drugs," International Journal of Traditional Chinese Medicine, vol. 34, no. 1, pp. 80-82, 2012 (Chinese).

[13] National Pharmacopoeia Editorial Board: Pharmacopoeia of china, Beijing: China Medical Science and Technology Press, 2015.

[14] X.-M. Hu, S. Tanaka, K. Onda et al., "Arsenic disulfide induced apoptosis and concurrently promoted erythroid differentiation in cytokine-dependent myelodysplastic syndrome-progressed leukemia cell line F-36p with complex karyotype including monosomy 7," Chinese Journal of Integrative Medicine, vol. 20, no. 5, pp. 387-393, 2014.

[15] X.-M. Hu, B. Yuan, S. Tanaka et al., "Involvement of oxidative stress associated with glutathione depletion and p38 mitogenactivated protein kinase activation in arsenic disulfide-induced differentiation in HL-60 cells," Leukemia \& Lymphoma, vol. 55, no. 2, pp. 392-404, 2014.

[16] X. M. Hu, B. Yuan, S. Tanaka et al., "Arsenic disulfide-triggered apoptosis and erythroid differentiation in myelodysplastic syndrome and acute myeloid leukemia cell lines," International Journal of Hematology, vol. 19, no. 6, pp. 352-360, 2014.

[17] X. M. Hu, Y. Bo, M. M. Song et al., "Dose-dependent biphasic effects of arsenic disulfideon differentiation and apoptosis of HL-60 cells," Current Topics in Pharmacology, vol. 17, no. 2, pp. 13-25, 2014. 


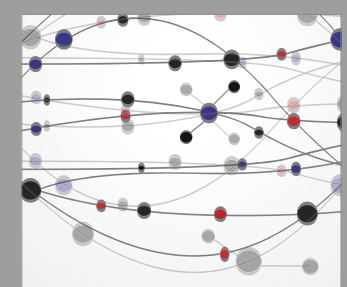

The Scientific World Journal
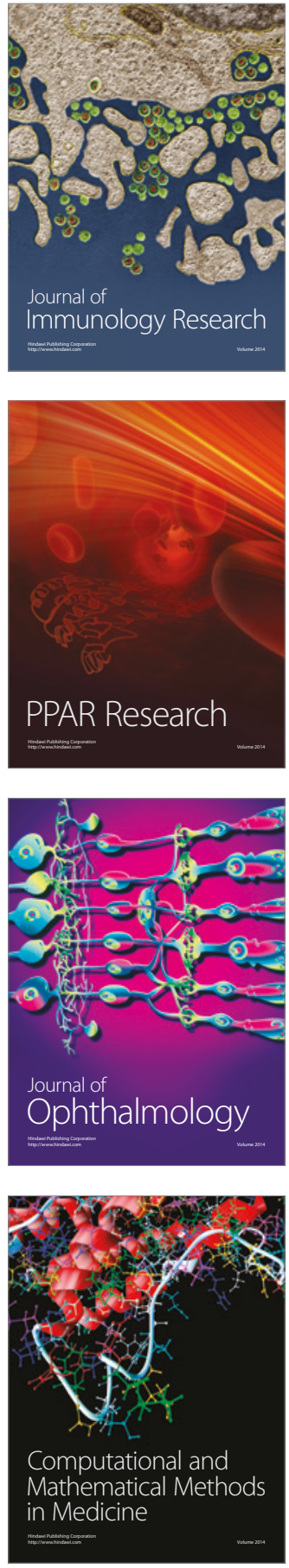

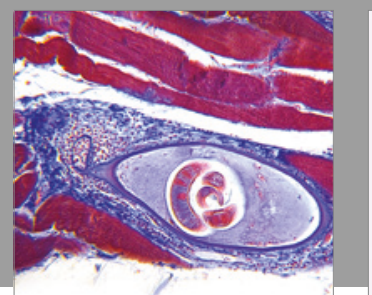

Gastroenterology Research and Practice
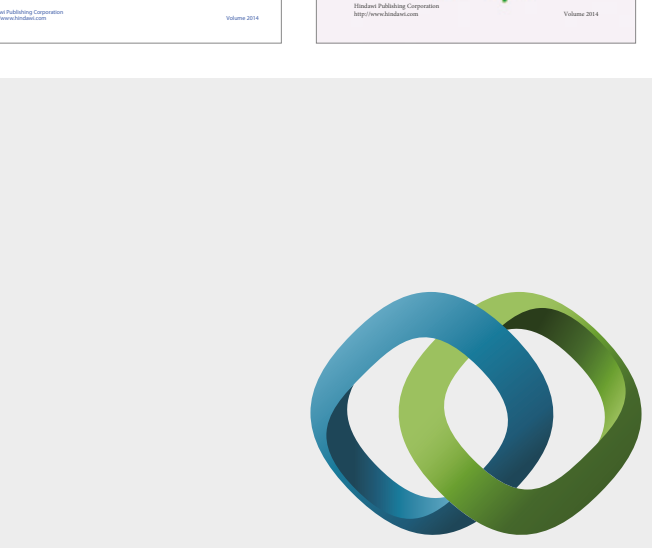

\section{Hindawi}

Submit your manuscripts at

https://www.hindawi.com
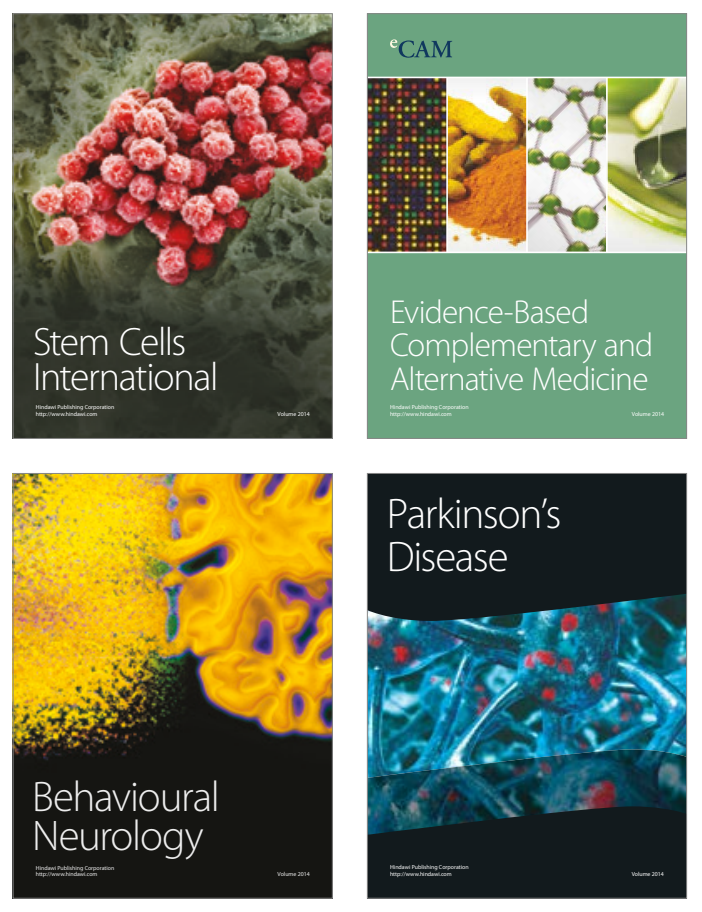
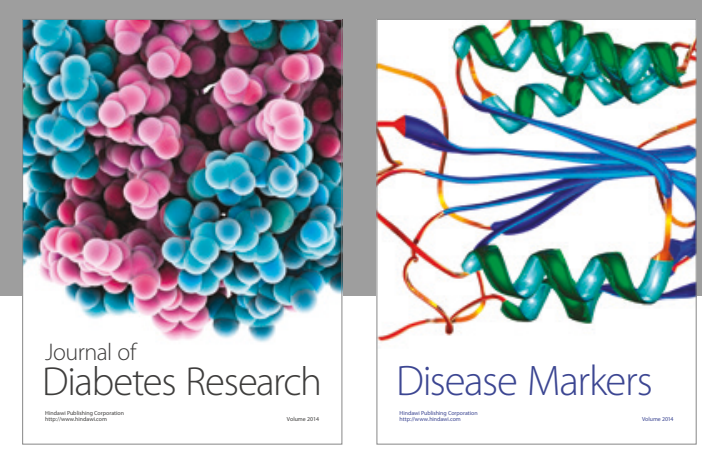

Disease Markers
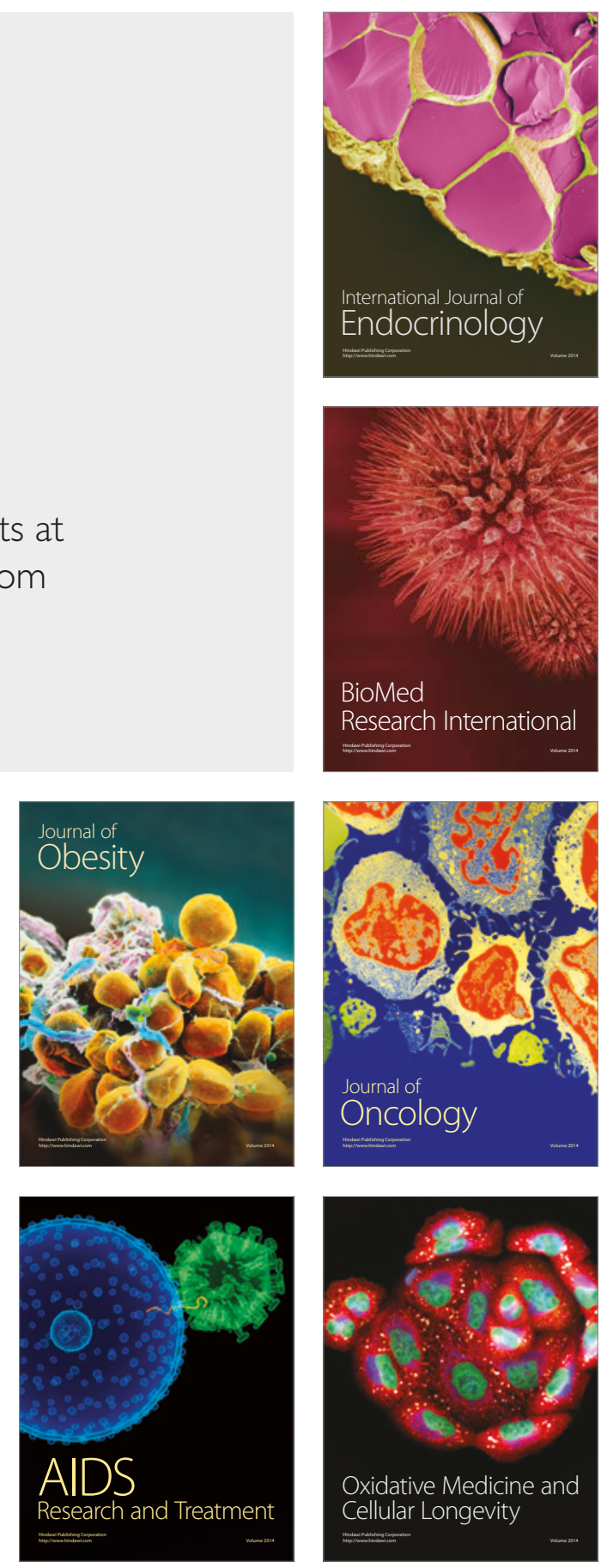